\title{
Size-dependent photocurrent switching in chemical bath deposited CdSe quantum dot films
}

\author{
M. V. Malashchonak ${ }^{1}$ - E. A. Streltsov ${ }^{1}$ A. V. Mazanik $^{1}$ - A. I. Kulak ${ }^{2}$ • \\ M. B. Dergacheva ${ }^{3}$ K. A. Urazov ${ }^{3}$ V. V. Pilko ${ }^{1}$
}

Received: 21 September 2016 / Revised: 13 October 2016 / Accepted: 18 October 2016

(C) Springer-Verlag Berlin Heidelberg 2016

\begin{abstract}
Size-dependent photocurrent switching has been investigated in chemical bath deposited CdSe quantum dot (QD) films with band gaps 2.26, 2.09, and $1.81 \mathrm{eV}$ (corresponds to nanoparticles' average diameter of 4,5 , and $10 \mathrm{~nm}$ ). CdSe films generate only anodic photocurrent (exhibit $n$-type semiconductor behavior) in the solution which contains only acceptor of photoholes $\left(\mathrm{SO}_{3}{ }^{2-}\right.$ anions), whereas cathodic photocurrent (corresponding to $p$-type behavior) arises after immersion of the films in polyselenide electrolyte (containing $\mathrm{Se}_{\mathrm{n}}{ }^{2-} / \mathrm{Se}^{2-}$ redox system). Appearance of the cathodic photocurrent is related to chemisorptions of $\mathrm{Se}^{2-}$ and $\mathrm{Se}_{\mathrm{n}}{ }^{2-}$ anions, as revealed by the cadmium underpotential deposition (UPD). Photocurrent switching from anodic to cathodic becomes more pronounced with decreasing of CdSe nanoparticle size because small quantum dots with their broadened band gaps have more favorable conduction band energy for electron injection to polyselenide anions. On the contrary, particle size does not play a significant role for the injection of photoholes into the electrolyte because the position of the valence band is weakly size-dependent, and anodic photocurrent is determined primarily by the real surface area of the electrode, which was found to be greater than the geometrical one by 1-2 orders of magnitude from cadmium UPD. Effective charge separation at the highly developed CdSe-electrolyte
\end{abstract}

M. V. Malashchonak

che.malasche@gmail.com

1 Belarusian State University, Nezalezhnastsi Av. 4, 220030 Minsk, Belarus

2 Institute of General and Inorganic Chemistry, National Academy of Sciences of Belarus, Surganov St. 9/1, 220072 Minsk, Belarus

3 Sokolsky Institute of Fuel, Catalysis and Electrochemistry, Almaty, Kazakhstan interface contributes to high incident photon-to-current conversion efficiency of photocurrent (IPCE $40 \%$ ).

Keywords CdSe - Quantum dots · Chemical bath deposition · Photocurrent switching · Underpotential deposition

\section{Introduction}

In recent decades, there has been a great interest in the study of physical, chemical, and optical properties of semiconductor nanocrystals (or quantum dots, QDs), in particular, cadmium selenide CdSe [1-11]. It is caused by numerous potential applications of this semiconductor: photovoltaics [1-5], photocatalysis [6-9], and optoelectronics [10, 11]. CdSe QDs have been employed in three different types of quantum dot solar cells: (i) quantum dot-sensitized solar cells, (ii) polymer hybrid solar cells, and (iii) metal junction solar cells [12]. By changing the size of CdSe QDs, one can not only vary the spectral sensitivity of solar cells but also improve their efficiency.

Chemical bath deposited (CBD) CdSe QDs usually form highly porous films which consist of a "network" of nanoparticles, display a blue shift in absorption spectra, and splitting of the bands into discrete levels as the QD size decreases [13, 14]. Such films possess a number of characteristics that distinguish them from the films obtained by other methods (e.g., using colloidal QDs). CBD CdSe films are characterized by an intimate contact between neighboring nanocrystals, which promotes charge transport over them [13]. At the same time, the porosity of the films allows the majority of nanoparticles to contact with the electrolyte. As a result, these films operate due to charge separation at the semiconductor-electrolyte interface rather than by a built-in space charge region as 
normally occurs in photoelectrochemical (PEC) cells with bulk semiconductor $[15,16]$.

The type of PEC behavior of CdSe QDs is determined by what charges are moving into the solution: if the components of electrolyte capture photoholes, the anodic photocurrent is observed (oxidation of a reducing agent in the solution) [15]. In this case, photoelectrons move through the QDs into the conductive substrate, which corresponds to the $n$-type behavior. The cathodic photocurrent ( $p$-type behavior) for the QDs is less common, because holes are characterized by significantly lower mobility, which increases the probability of recombination during their transfer to the conductive substrate. Hodes and coworkers have shown that treating of CdSe QDs surface in dilute $\mathrm{HCl}$ changes their PEC behavior from $n$-type like to $p$-type like, which is caused by surface modification-induced changes in the kinetics of charge transfer to the polysulfide electrolyte $[13,15]$. The surface photovoltage spectroscopy shows that the CdSe QD films exhibit $p$-type properties after etching only in a humid ambient, whereas in a dry ambient they are $n$-type-like [17]. This fact indicates that the dominating type of surface traps (hole or electron) depends on the ambient. It was also suggested that the change in the type of CdSe QDs PEC behavior can be associated with enrichment of nanoparticles surface with selenium atoms [17]. Nevertheless, factors affecting the photocurrent sign, as well as quantum efficiency of PEC processes in CdSe QD films are still not completely clear.

Therefore, the purposes of this study were as follows: (i) to investigate the PEC behavior changes of CdSe QD films from $n$-type like to $p$-type like caused by formation of Seterminated surface; (ii) to clarify the influence of CdSe nanoparticles size on photocurrent switching effect; (iii) to reveal factors determining efficiency of PEC processes in the CBD CdSe QD films.

\section{Experimental section}

Chemical deposition of CdSe QD films was carried out as described in [13-15]. FTO conductive glass was used as substrate for electrochemical measurements, and glass without FTO-for optical absorption, X-ray diffraction (XRD), Rutherford backscattering, Raman, and photoluminescence (PL) experiments. The films were deposited from an aqueous solution containing $80 \mathrm{mM} \mathrm{Na}_{2} \mathrm{SeSO}_{3}(0.2 \mathrm{~mol}$ of black selenium powder dissolved in $0.5 \mathrm{M} \mathrm{Na}_{2} \mathrm{SO}_{3}$ at $65{ }^{\circ} \mathrm{C}$ ), $80 \mathrm{mM}$ $\mathrm{CdSO}_{4}$, and $150-170 \mathrm{mM}$ potassium nitrilotriacetate $\mathrm{N}\left(\mathrm{CH}_{2} \mathrm{COOK}\right)_{3}$ as a complexing agent. The $\mathrm{pH}$ of the solution was adjusted to 10.0 with $2 \% \mathrm{KOH}$. CdSe film deposition was carried out in the dark at three different solution temperatures 3,30 , and $80^{\circ} \mathrm{C}$. These films will be denoted as $\mathrm{CdSe}(3), \mathrm{CdSe}(30)$, and $\mathrm{CdSe}(80)$, respectively. According to [13-15], an increase in temperature of the solution increases the size of the CdSe particles, as well as the deposition rate. In order to obtain a comparable thickness of the films grown at different temperatures, deposition time was chosen equal to 40,18 , and $14 \mathrm{~h}$ for deposition temperatures 3,30 , and $80^{\circ} \mathrm{C}$, respectively. The thickness of prepared films according to SEM was a few hundred nanometers.

SEM images of CdSe films surface were obtained on Hitachi S 4800 field emission scanning electron microscope. TEM studies of CdSe nanoparticles were performed on LEO906E transmission electron microscope. CdSe nanoparticles were carefully scraped from FTO substrate, ultrasonically dispersed in distilled water, and transferred to copper grids covered with collodion film for TEM measurements.

Photoelectrochemical measurements were fulfilled in a standard three electrode cell involving a platinum counterelectrode and an $\mathrm{Ag}|\mathrm{AgCl}| \mathrm{KCl}$ (sat.) electrode (+0.201 V vs standard hydrogen electrode (SHE)) as the reference one. All electrode potentials in the article are given with respect to SHE. Electrode potential was controlled with an Elins P-8 (Russia) potentiostat. Photocurrent spectra were obtained using a setup equipped with a high-intensity grating monochromator (spectral resolution $1 \mathrm{~nm}$ ), a $250 \mathrm{~W}$ halogen lamp, and a light chopper. The spectral dependences of the incident photon-to-current conversion efficiency (IPCE, $Y$ ) were calculated from the photocurrent spectra and light intensity distribution at the monochromator output. Electrodes were illuminated from the conductive FTO substrate side to minimize the light absorption by electrolyte solutions. All solutions used were thoroughly purged with argon prior to and during the electrochemical and photoelectrochemical experiments.

XRD analysis was carried out with a Bruker D8 Advance diffractometer (Bragg-Brentano geometry, $\mathrm{Cu} \mathrm{K}_{\alpha}$ emission, $0.5^{\circ} / \mathrm{min}$ ). Raman and PL spectra were measured at room temperature using a Nanofinder HE confocal spectrometer (LOTIS TII, Belarus-Japan) with 532 and $473 \mathrm{~nm}$ solid-state cw lasers as excitation sources. Incident optical power was attenuated to $\approx 20 \mu \mathrm{W}$ to minimize a thermal impact. Backscattered light without analysis of its polarization was dispersed with a spectral resolution of $2.5 \mathrm{~cm}^{-1}(0.1 \mathrm{~nm})$ and detected with a cooled CCD-matrix. Signal acquisition time was equal to $120 \mathrm{~s}$. The excitation spot diameter was about $1 \mu \mathrm{m}$. Spectral calibration was done using a built-in gas-discharge lamp providing accuracy better than $2.5 \mathrm{~cm}^{-1}(0.1 \mathrm{~nm})$. Rutherford backscattering spectrometry (RBS) was carried out using $1.3 \mathrm{MeV} \mathrm{He}^{+}$ions (scattering angle $\theta=170^{\circ}$ ).

\section{Results and discussion}

\section{XRD and optical characterization of CdSe films}

CdSe films obtained at different deposition bath temperatures are characterized by a different color-from yellow to blackbrown. Absorption spectra are shown in Fig. 1. There is a clear 


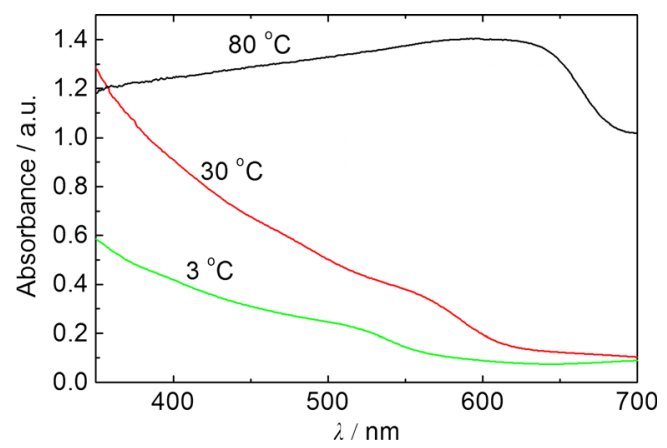

Fig. 1 Absorption spectra of the CdSe films deposited at 3, 30, and $80^{\circ} \mathrm{C}$

blue shift of the absorption edge with decreasing of deposition temperature. These results are fully consistent with previous studies [13-15] and are caused by synthesis of CdSe nanoparticles with different sizes and hence with different band gaps. It should also be noted that $\mathrm{CdSe}(80)$ demonstrates a pronounced light scattering.

SEM images of surface of prepared CdSe films are presented in Figs. 2a-c. The films are quite uniform, and sponge-like structure of $\mathrm{CdSe}(30)$ film can be seen. TEM images on Figs. $2 \mathrm{~d}-\mathrm{f}$ show that the films are composed of polydisperse nanoparticles. CdSe nanoparticles of several nanometers in diameter are predominant for $\mathrm{CdSe}(3)$ and $\mathrm{CdSe}(30)$ films, whereas for $\mathrm{CdSe}(80)$ significantly larger particles can be distinguished- $10 \mathrm{~nm}$ and bigger. Nevertheless, it should be noted, that quantitative determination of nanoparticle diameter from TEM images is pretty difficult. Apparently, it is caused by the intimate contact of nanoparticles deposited by CBD which results in a continuous net of crystallites (aggregates) strongly bonded with each other. From one hand, it makes hard to distinguish a separate nanoparticle, but from the other hand, it provides an efficient transport of photogenerated charge carriers through the film. Thus, we have made a quantitative estimation of average diameter of nanoparticles prepared at different deposition temperature on the basis of photocurrent spectroscopy data (see below).

$\mathrm{X}$-ray analysis shows that crystallinity of the CdSe films increases with the temperature of their deposition, as can be seen by an increase in the intensity of reflections and reduction of their width (Fig. 3a). It is known that cadmium selenide can crystallize both in hexagonal and cubic modifications [18]. In our case, the large width of the reflections for $\mathrm{CdSe}(3)$ and $\mathrm{CdSe}(30)$ does not allow determining the type of their crystal structure for sure, whereas $\mathrm{CdSe}(80)$ is clearly related to the hexagonal crystal modification.

Raman spectra of the films (Fig. 3b) have a band at $207 \mathrm{~cm}^{-1}$, which corresponds to a scattering by longitudinal optical (LO) phonons in CdSe [18], as well as two of its overtones (2LO and 3LO). The increase of CdSe films deposition temperature leads to a gradual reduction in the width of the CdSe LO band (from 17 to $12 \mathrm{~cm}^{-1}$ ), which is in agreement with improvement of crystallinity mentioned above. It may seem strange that there is no increase in the CdSe LO band intensity. However, this fact is naturally explained by a decrease of the band gap of $\mathrm{CdSe}$, and an increase in the difference between its value and the photon energy $(2.33 \mathrm{eV})$ used for excitation in Raman measurements. A similar effect was observed for the CdS nanoparticles with increasing of their size $[19,20]$.

As can be seen from Fig. 3c, PL spectra of the CdSe films deposited at low temperatures $(\mathrm{CdSe}(3)$ and $\mathrm{CdSe}(30))$ have
Fig. 2 SEM images of CdSe film surface $(\mathbf{a}-\mathbf{c})$ and TEM images of CdSe QDs. a, d CdSe(3). b, e $\mathrm{CdSe}(30) . \mathbf{c}, \mathbf{f} \mathrm{CdSe}(80)$
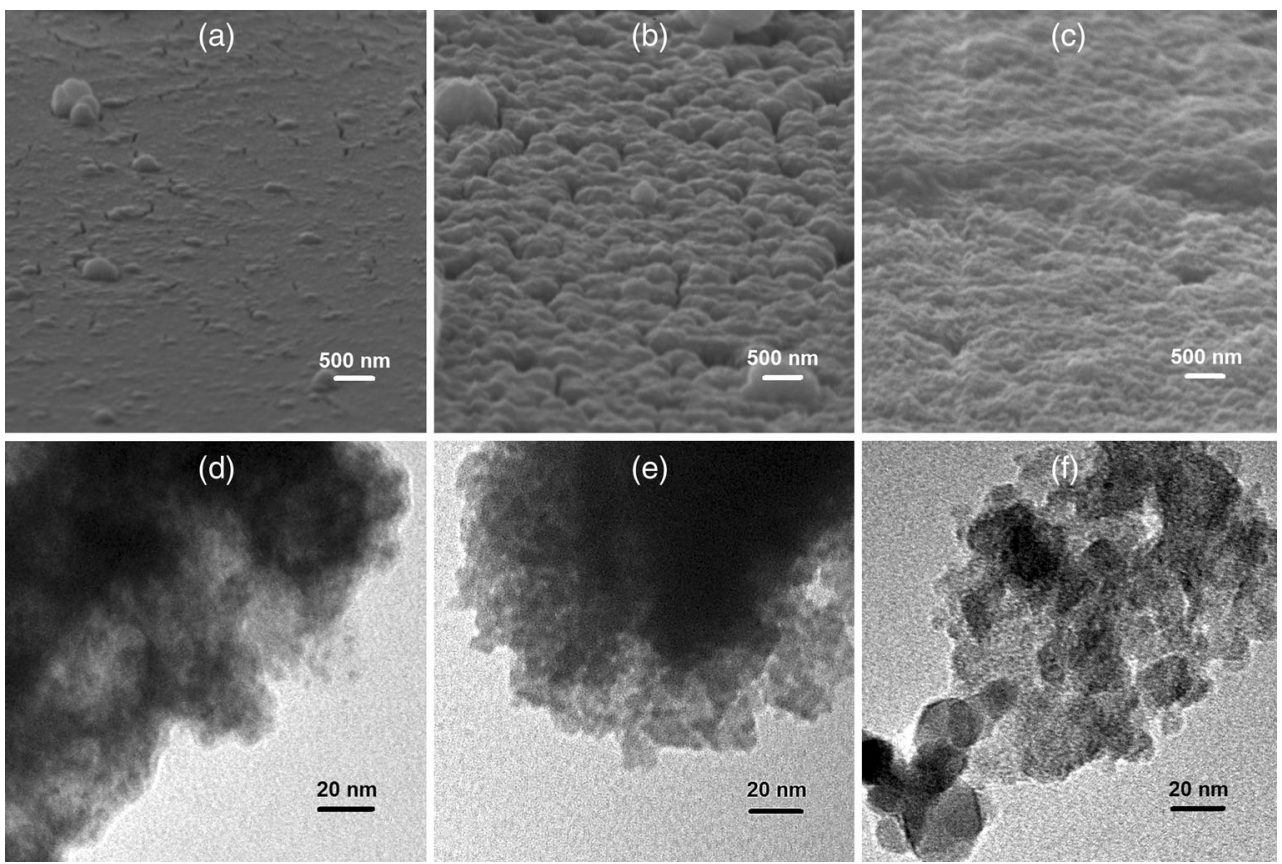
Fig. 3 X-ray diffraction patterns (a), Raman (b), and PL spectra (c) of CdSe films deposited at different deposition bath temperatures. Excitation $532 \mathrm{~nm} /$ $20 \mu \mathrm{W}(\mathbf{b}) ; 473 \mathrm{~nm} / 24 \mu \mathrm{W}$ (c)
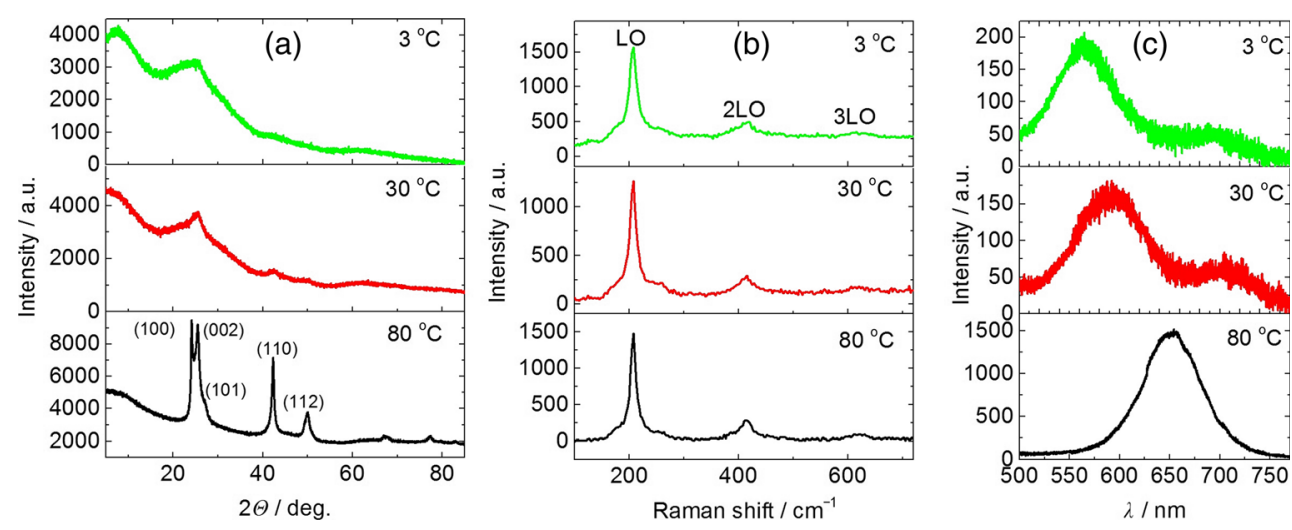

two bands. The position of the high-energy band enables one to associate it with the interband radiative recombination in the cadmium selenide nanoparticles, while the low-energy band corresponds to the radiative recombination through energy levels in the band gap of CdSe [21]. Raising the CdSe films deposition temperature from 3 to $80^{\circ} \mathrm{C}$ leads to a shift of the interband radiative recombination band from 560 to $650 \mathrm{~nm}$, which is in a qualitative agreement with the absorbance spectra (Fig. 1) and indicates a weakening of the quantum confinement in the CdSe nanoparticles. The disappearance of the low-energy component in the CdSe(80) PL spectra indicates the decrease of CdSe structural disorder with elevation of the deposition bath temperature correlating with a decrease in the spectral band width of interband radiative recombination, an increase in its intensity, as well as with the results of Raman and XRD analyzes.

\section{Photoelectrochemical properties of CdSe films in $\mathrm{Na}_{2} \mathrm{SO}_{3}$ solution}

CdSe QD films generate in $\mathrm{Na}_{2} \mathrm{SO}_{3}$ solution only anodic photocurrent under actinic illumination because this solution contains an effective acceptor of photoholes (sulfite anions), whereas there is no acceptor of photoelectrons (oxygen was removed by Ar purging). Thus, cadmium selenide demonstrates photoelectrochemical properties of $n$-type semiconductor: photoelectrons move through the nanoparticles into the conductive FTO substrate while photoholes oxidize sulfite anions.

Electron quantum-confinement effect for CdSe QD films is observed in the IPCE spectra (Fig. 4a). It is evident from the increase of the band gap $\left(E_{\mathrm{g}}\right)$ from 1.81 to $2.26 \mathrm{eV}$ when the deposition temperature decreases from 80 to $3{ }^{\circ} \mathrm{C}$ (Table 1 ). The $E_{\mathrm{g}}$ values were determined by extrapolation of the linear part of the $(Y h v)^{2}-h v$ plot (direct optical transitions, Fig. $4 \mathrm{~b}$ ). As can be seen from Table 1, the nanoparticles average diameter $(d)$ for $\mathrm{CdSe}(80)$ film estimated from $E_{\mathrm{g}}$ value $[22,23]$ increases more than twofold as compared to $\mathrm{CdSe}(3)$.
The deposition temperature affects not only the band gap of CdSe but also the value of IPCE (Fig. 4a). It was unexpected result that the maximum IPCE values are observed for $\mathrm{CdSe}(30)$, and minimal-for $\mathrm{CdSe}(80)$ films. The impact of various factors (particle size, film thickness, the depth of light penetration, etc.) on IPCE was analyzed earlier taking into account their influence on recombination as photocurrent loss mechanism [14, 15]. However, it will be demonstrated below that in our case there is an additional important factor affecting IPCE value - real surface area of CdSe film.

Photopolarization curves show that the anodic photocurrent saturates with the increase of anodic polarization of electrode, and the potential of photocurrent onset $\left(E_{\mathrm{on}}\right)$ takes more positive values with the increase in size of CdSe QDs (Fig. 5a). The observed $E_{\text {on }}(d)$ dependence can be explained in the following way. If the anodic photocurrent flows, the photoelectrons are transferred to the FTO substrate. Under the electrochemical polarization this process is possible if the Fermi level of the conductive glass is more positive than the electron quasi-Fermi level $\left(E_{\mathrm{Fn}}\right)$ of CdSe, which is usually considered as located close to conduction band edge $\left(E_{\mathrm{c}}\right)$. Hence, while shifting the Fermi level of the FTO substrate up during the cathodic scan of electrode potential, one should observe the disappearance of photocurrent when it reaches $E_{\mathrm{c}}$ of CdSe nanoparticles [24]. Therefore, the observed cathodic shift of $E_{\text {on }}$ with decrease of CdSe QD size indicates shift of their $E_{\mathrm{c}}$ to a higher energy. We have used the $E_{\text {on }}$ values to estimate the position of the conduction band edge of $\mathrm{CdSe}$ nanoparticles depending on their size. For $\mathrm{CdSe}(3)$ nanoparticles with $4 \mathrm{~nm}$ average diameter, the conduction band potential was estimated to be $-0.75 \mathrm{~V}$ (Fig. $5 \mathrm{~b}$ ). The conduction band shifts to positive potentials with the increase of particles size $(-0.57 \mathrm{~V}$ for $5 \mathrm{~nm}$ particles and $-0.23 \mathrm{~V}$ for $10 \mathrm{~nm}$ particles). The position of the valence band $\left(E_{\mathrm{v}}\right)$ was determined based on the $E_{\mathrm{c}}$ and $E_{\mathrm{g}}$ values. Figure 5 b shows clearly that the reduction of particles size influences on the position of $E_{\mathrm{c}}$ much stronger than on $E_{\mathrm{v}}$. In other words, most of the band gap increase is due to the shift of the conduction band edge to more negative potentials. This situation is typical for $\mathrm{CdSe}$ 
Fig. 4 Spectra of anodic photocurrent in $Y-\lambda(\mathbf{a})$ and $(Y \times h v)^{2}-h v(\mathbf{b})$ coordinates: 1 $\mathrm{CdSe}(3), 2 \mathrm{CdSe}(30)$, and 3 $\mathrm{CdSe}(80)$. The solution is $0.1 \mathrm{M}$ $\mathrm{Na}_{2} \mathrm{SO}_{3}$. Applied potential is $0.2 \mathrm{~V}$

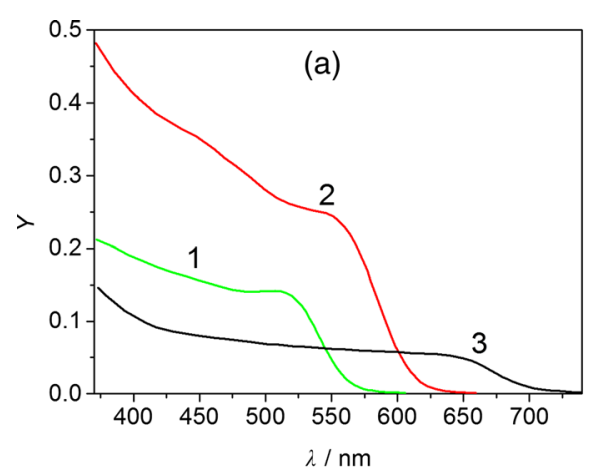

[25, 26], as well as for CdS [27], CdTe [28], and $\mathrm{ZnO}$ [29] QDs and is naturally attributed to a significant difference in the effective masses of electrons and holes.

Note that the obtained $E_{\mathrm{c}}$ and $E_{\mathrm{v}}$ values are anodically shifted by appr. $0.5 \mathrm{~V}$ in comparison with the values provided by theoretical calculations [30] and experimental findings (ultraviolet photoelectron emission spectroscopy [31-33], cyclic voltammetry in non-aqueous solutions [34-36]). Such discrepancy could be explained by (i) impact of recombination [24], (ii) influence of specific adsorption of ions and dipoles of solvent [31], and (iii) non-negligible difference between $E_{\mathrm{c}}$ and $E_{\mathrm{Fn}}$ for CdSe QDs. Nevertheless, the obtained constancy in $E_{\mathrm{v}}$ position regardless of the CdSe QD size is in a good agreement with the above-cited works [30-36].

The energy level corresponding to standard redox potential of the $\mathrm{SO}_{4}{ }^{2-} / \mathrm{SO}_{3}{ }^{2-}$ redox system $(-0.47 \mathrm{~V}, \mathrm{pH} 9.3)$ is located far enough from the valence band of CdSe (even if $E_{\mathrm{c}}$ and $E_{\mathrm{v}}$ have more negative potentials in comparison with the data presented in Fig. 5b). Thus, the size of the nanoparticles should have no influence on the rate of photoelectrochemical oxidation process, as the photoholes generated in the valence band have a sufficient energy for injection into electrolyte from particles of any size. Therefore, we can assume that high quantum efficiency for the anodic photoelectrochemical process which takes place on the surface of nanocrystalline $\mathrm{CdSe}$ films can be achieved not by means of the band-edge tuning of cadmium selenide quantum dot particles but primarily due to an effective charge separation at the semiconductor-electrolyte interface. Thereby, we need to have information about the real surface area of photoelectrodes and an appropriate method for its evaluation.

Table 1 Band gap $\left(E_{\mathrm{g}}\right)$, average particle diameter $(d)$, and onset potential $\left(E_{\text {on }}\right)$ for CdSe QDs deposited at different temperatures

\begin{tabular}{lccl}
\hline QD film & $E_{\mathrm{g}}, \mathrm{eV}$ & $d, \mathrm{~nm}$ & $\begin{array}{l}E_{\mathrm{on}}, \mathrm{V} \\
0.1 \mathrm{M} \mathrm{Na}_{2} \mathrm{SO}_{3}\end{array}$ \\
\hline $\mathrm{CdSe}(3)$ & 2.26 & 4 & -0.75 \\
$\mathrm{CdSe}(30)$ & 2.09 & 5 & -0.57 \\
$\mathrm{CdSe}(80)$ & 1.81 & 10 & -0.23 \\
\hline
\end{tabular}

\section{Cadmium underpotential deposition on CdSe QD films}

To estimate the real surface area of the CdSe QD films, the cadmium UPD process was used. Classically, UPD involves deposition of a less noble element (most often, metal) on a more noble substrate and is limited to the formation of $2 \mathrm{D}$ atomic layers (monolayers) [37-39]. The phenomenon of $\mathrm{Cd}$ UPD on CdSe is well-documented [40-43]. It involves the deposition of $\mathrm{Cd}$ atomic layers on $\mathrm{Se}$ atoms in the crystal lattice of $\mathrm{CdSe}$ at a potential prior to (under) that required for deposition of the $\mathrm{Cd}$ on itself and is widely used for the electrosynthesis of $\mathrm{CdSe}$ in the electrochemical atomic layer epitaxy (ECALE) method [44]. Since UPD is a surfacelimited process, the passed electrical charge makes it possible to estimate the real electrode surface area (roughness factor$f$ ) assuming the formation of cadmium adatoms monolayer [45].

Cyclic voltammograms (CVA) of $\mathrm{Cd}^{2+}$ cathodic reduction and anodic oxidation of metal $\left(\mathrm{Cd}^{0}\right)$ for the $\mathrm{CdSe}(30)$ electrode are shown in Fig. 6. CVA for $\mathrm{CdSe}(3)$ and $\mathrm{CdSe}(80)$ are qualitatively similar.

The equilibrium redox potential $E\left(\mathrm{Cd}^{2+} / \mathrm{Cd}^{0}\right)$ calculated according to the Nernst equation is $-0.48 \mathrm{~V}$. There is no cathodic current in the solution which contains no $\mathrm{Cd}^{2+}$ cations $\left(0.1 \mathrm{M} \mathrm{Na}_{2} \mathrm{SO}_{4}, \mathrm{pH} 4\right)$ in the studied potential range (Fig. 6, curve 1). Therefore, the cathodic current observed during the cathodic scan at $E>E\left(\mathrm{Cd}^{2+} / \mathrm{Cd}^{0}\right)$ is associated with the cadmium UPD process.

The formation of metal phase occurs at $E<-0.60 \mathrm{~V}$ (Fig. 6, curves 3,4$)$, i.e., is characterized by a sufficiently large $(0.12 \mathrm{~V})$ overvoltage. Bulk cadmium is oxidized at the anodic scan of potential giving the characteristic anodic current peak. It should be noted that in contrast to the bulk metal, cadmium adatoms are not oxidized during the anodic scan (Fig. 6, curve 2), i.e., the UPD is irreversible. Thus, the cadmium UPD on the CdSe QD electrodes can be carried out only once. As a result, CdSe surface becomes enriched with cadmium atoms (Cd-terminated surface).

Assuming that the surface concentration of cadmium adatoms in the monolayer is about $10^{15}$ at $/ \mathrm{cm}^{2}$, we can estimate the amount of charge required for its formation. 
Fig. 5 a The dependences of IPCE on electrode potential: 1 $\mathrm{CdSe}(3), 2 \mathrm{CdSe}(30)$, and 3 $\mathrm{CdSe}(80)$; excitation light wavelength $530 \mathrm{~nm}$; solution $0.1 \mathrm{M} \mathrm{Na}_{2} \mathrm{SO}_{3}$. b Energy diagram for CdSe QDs of different sizes in $\mathrm{Na}_{2} \mathrm{SO}_{3}$ solution

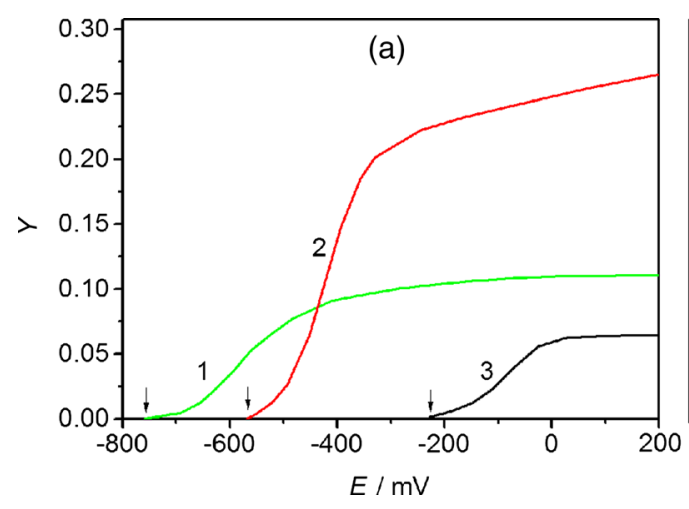

Considering that the reduction of $\mathrm{Cd}^{2+}$ cation requires two electrons, we can get a charge of $0.32 \mathrm{mC} / \mathrm{cm}^{2}$. The charges under the cathodic potentiodynamic curves (calculated up to the potential of the metal phase formation $-0.60 \mathrm{~V}$ ), and the factors of electrode surface roughness $f$ are shown in Table 2. The obtained $f$ values suggest that the CBD CdSe films have an extremely large real surface area, which is 1-2 orders of magnitude (!) greater than the geometric surface area of the electrode. The largest area of contact with electrolyte solution is observed for $\mathrm{CdSe}(30)$ which correlates with the largest anodic IPCE values for these films (Fig. 4a) and their globular structure (Fig. 2b).

\section{Cathodic photocurrent in polyselenide solution}

It is well known that CdSe QDs have high quantum efficiency and photocorrosion stability in the polysulfide electrolyte [46]. Photocurrent switching for CdSe was observed in this electrolyte after etching in dilute $\mathrm{HCl}[15,17]$. However, we declined purposely to use this electrolyte because it was clearly proved that the surface of CdSe changes its chemical

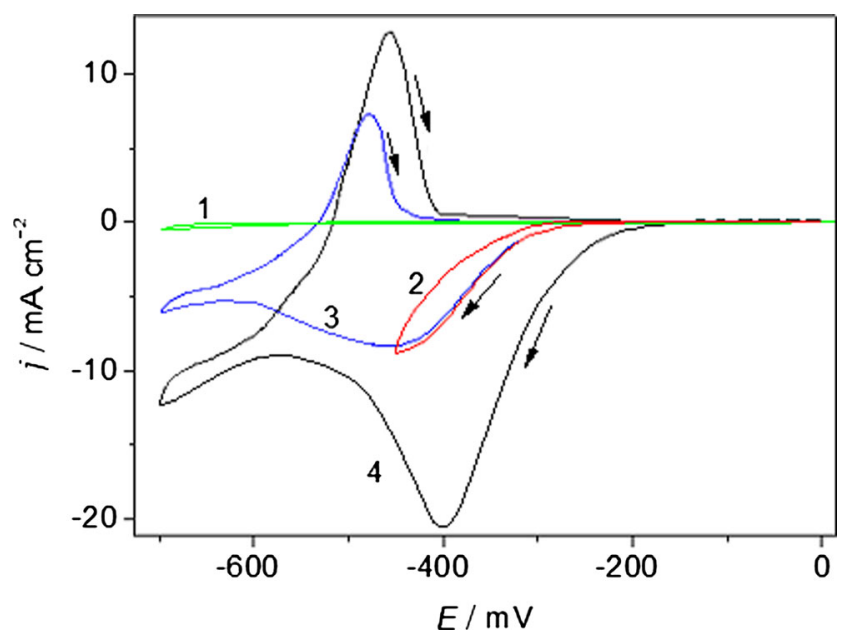

Fig. 6 Cyclic voltammograms for $\mathrm{CdSe}(30)$ : 1 in the solution of $0.1 \mathrm{M}$ $\mathrm{Na}_{2} \mathrm{SO}_{4}(\mathrm{pH} 4) ; 2-4$ in the solution of $0.01 \mathrm{M} \mathrm{CdSO}_{4}+0.1 \mathrm{~N} \mathrm{Na}_{2} \mathrm{SO}_{4}$ (pH 4). The solutions were saturated with Ar. 1-3 as-deposited, 4 after selenization. Potential scan rate is $50 \mathrm{mV} / \mathrm{s}$ composition forming a $\mathrm{CdS} / \mathrm{CdSe}$ heterojunction in this solution $[12,46]$.

For cathodic photocurrent investigation, we have used the polyselenide electrolyte containing $0.02 \mathrm{M} \mathrm{Se}, 10 \mathrm{M} \mathrm{NaOH}$, $0.2 \mathrm{M} \mathrm{Na}_{2} \mathrm{SO}_{3}$, and $0.1 \mathrm{M} \mathrm{Na}_{2} \mathrm{SeSO}_{3}$. Selenide $\left(\mathrm{Se}^{2-}\right)$ and polyselenide $\left(\mathrm{Se}_{\mathrm{n}}{ }^{2-}\right)$ are formed by the following reactions:

$$
\begin{aligned}
& 3 \mathrm{Se}+6 \mathrm{OH}^{-}=2 \mathrm{Se}^{2-}+\mathrm{SeO}_{3}{ }^{2^{-}}+3 \mathrm{H}_{2} \mathrm{O}, \\
& (\mathrm{n}-1) \mathrm{Se}+\mathrm{Se}^{2-}=\mathrm{Se}_{\mathrm{n}}{ }^{2-} .
\end{aligned}
$$

Concentrated alkali solution is necessary for efficient elemental selenium disproportionation, as well as for suppressing of the hydrolysis reactions. In this case, we are dealing with a reversible redox system with both the acceptor of photoholes $\left(\mathrm{Se}^{2-}\right)$ and photoelectrons acceptor $\left(\mathrm{Se}_{\mathrm{n}}{ }^{2-}\right)$. It allows us to study the effect of photocurrent switching (changing its sign). Photocorrosion stability of CdSe QD electrodes in this electrolyte is sufficiently high. It is essential to minimize the effects associated with nanoparticles photocorrosion, dissolving, and, consequently, changing of their size.

$\mathrm{Na}_{2} \mathrm{SO}_{3}$ and $\mathrm{Na}_{2} \mathrm{SeSO}_{3}$ were also added to the electrolyte. Firstly, $\mathrm{SO}_{3}{ }^{2-}$ and $\mathrm{SeSO}_{3}{ }^{2-}$ anions along with $\mathrm{Se}^{2-}$ are effective photoholes scavengers. Secondly, sulfite removes traces of molecular oxygen from the solution, and $\mathrm{SO}_{3}{ }^{2-} / \mathrm{SeSO}_{3}{ }^{2-}$ pair prevents precipitation of elemental selenium by its binding in selenosulfate.

There is a significant change in PEC behavior of the CdSe QD films in polyselenide electrolyte as compared to $\mathrm{Na}_{2} \mathrm{SO}_{3}$ solution. Photopolarization curves in Fig. 7 obtained by subtracting the dark current from the total current observed under illumination demonstrate that the $\mathrm{CdSe}$ electrodes generate cathodic

Table 2 The charge of UPD deposited cadmium adatoms $\left(Q_{\mathrm{UPD}}\right)$ and the roughness factor $(f)$ for the CdSe films obtained at different deposition bath temperatures; solution contains $0.01 \mathrm{M} \mathrm{CdSO}_{4}+0.1 \mathrm{M}$ $\mathrm{Na}_{2} \mathrm{SO}_{4}, \mathrm{pH} 4$

\begin{tabular}{ccr}
\hline QD film & $Q_{\text {UPD }}, \mathrm{mC} / \mathrm{cm}^{2}$ & \multicolumn{1}{c}{$f$} \\
\hline $\mathrm{CdSe}(3)$ & 4.4 & 14 \\
$\mathrm{CdSe}(30)$ & 40.1 & 125 \\
$\mathrm{CdSe}(80)$ & 2.7 & 8 \\
\hline
\end{tabular}




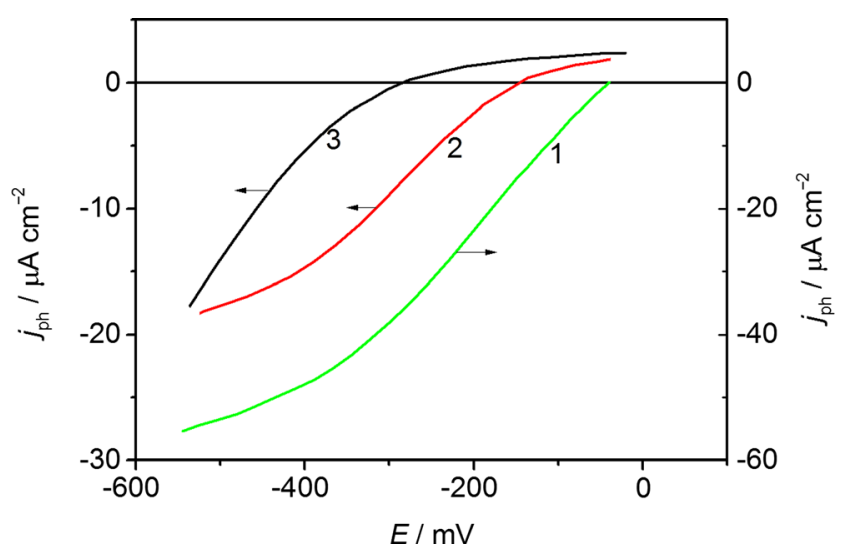

Fig. 7 The dependences of photocurrent density on the electrode potential for $\mathrm{CdSe}$ QD electrodes it the solution containing $0.02 \mathrm{M} \mathrm{Se}, 10 \mathrm{M} \mathrm{NaOH}$, $0.2 \mathrm{M} \mathrm{Na}_{2} \mathrm{SO}_{3}, 0.1 \mathrm{M} \mathrm{Na}_{2} \mathrm{SeSO}_{3} .1 \mathrm{CdSe}(3), 2 \mathrm{CdSe}(30)$, and $3 \mathrm{CdSe}(80)$. Excitation light wavelength is $530 \mathrm{~nm}\left(J=800 \mu \mathrm{W} / \mathrm{cm}^{2}\right)$. Potential scan rate is $5 \mathrm{mV} / \mathrm{s}$

photocurrent. $P$-type behavior means preferential photoelectron injection into the electrolyte. The effect of photocurrent switching is the most pronounced for $\mathrm{CdSe}(3)$ electrodes - in polyselenide electrolyte these electrodes demonstrate only cathodic photocurrent with the largest IPCE (Fig. 7). Cathodic photocurrent for $\mathrm{CdSe}(30)$ and $\mathrm{CdSe}(80)$ films is also dominant, but a minor anodic photocurrent can be detected as well. Furthermore, if on $\mathrm{CdSe}(3)$ cathodic photocurrent is registered immediately after immersion into the polyselenide electrolyte, for $\mathrm{CdSe}(30)$, just after the immersion of electrode into the electrolyte, a decreasing anodic photocurrent is observed and switching to cathodic photocurrent occurs after $10 \mathrm{~s}$ of contact with the electrolyte; for $\mathrm{CdSe}(80)$, photocurrent switching is observed only after 10 15 min. Such delay in appearance of cathodic photocurrent means that the presence of electron acceptor species in electrolyte is not enough for electron injection into solution and surface modification is necessary. It is logical to assume that photocurrent switching is related to enrichment of CdSe surface with selenium (Se-terminated surface). Se-terminated surface formation occurs due to the chemisorption of $\mathrm{Se}^{2-}$ and $\mathrm{Se}_{\mathrm{n}}{ }^{2-}$ on the surface of CdSe. This process is identical to the well known SILAR method used for CdSe nanoparticles synthesis [47]. The obtained results indicate a high rate of $\mathrm{Se}^{2-}$ and $\mathrm{Se}_{\mathrm{n}}{ }^{2-}$ chemisorption on the CdSe particles of a small size.

As a result of the formation of Se-terminated surface, the concentration of selenium surface atoms on CdSe nanoparticles increases. In order to verify this claim, cadmium UPD was carried out on the CdSe electrodes with Se-terminated surface. CdSe films treated in polyselenide electrolyte for $10 \mathrm{~s}$ and washed with $10 \mathrm{M}$ alkali (to prevent hydrolysis) and distilled water were immersed in a solution containing $\mathrm{Cd}^{2+}$ cations. Charges corresponding to the cathodic peaks $\left(Q_{\mathrm{UPD}}\right)$ on $\mathrm{CdSe}$ electrodes with Se-terminated surface are shown in Table 3. A significant increase in $Q_{\mathrm{UPD}}$ values is observed for all CdSe films after surface selenization. The observed increase in the real
Table 3 Band gap $\left(E_{\mathrm{g}}\right)$, band gap decrease $\left(\Delta E_{\mathrm{g}}\right)$, the charge of UPD deposited cadmium adatoms $\left(Q_{\mathrm{UPD}}\right)$ and the roughness factor $(f)$ for the CdSe films with Se-terminated surface; solution for UPD experiments contains $0.01 \mathrm{M} \mathrm{CdSO}_{4}+0.1 \mathrm{M} \mathrm{Na}_{2} \mathrm{SO}_{4}, \mathrm{pH} 4$

\begin{tabular}{cclcr}
\hline QD film & $E_{\mathrm{g}}, \mathrm{eV}$ & $\Delta E_{\mathrm{g}}, \mathrm{eV}$ & $Q_{\mathrm{UPD}}, \mathrm{mC} / \mathrm{cm}^{2}$ & \multicolumn{1}{c}{$f$} \\
\hline $\mathrm{CdSe}(3)$ & 2.08 & 0.18 & 8.4 & 26 \\
$\mathrm{CdSe}(30)$ & 2.00 & 0.09 & 87.6 & 274 \\
$\mathrm{CdSe}(80)$ & 1.81 & 0 & 4.5 & 14 \\
\hline
\end{tabular}

surface for selenized CdSe QD films can be attributed to an increase in the concentration of selenium surface atoms on CdSe nanocrystals, as well as to an increase in the size of QDs due to the chemisorption of $\mathrm{Se}^{2-}$ and $\mathrm{Se}_{\mathrm{n}}{ }^{2-}$.

An additional direct evidence of Se concentration increase in the films after their treatment in the polyselenide electrolyte was obtained using RBS. As it is seen in Fig. 8, immersion in polyselenide electrolyte does not affect position of the Cdrelated high-energy peak indicating that no bulk selenium is formed on the electrode surface. At the same time, one can observe an enhancement of relative intensity of the Se-related peak and its low-energy broadening, which points to increase of selenium content in the film.

The growth of the CdSe QDs size as a result of selenization of the films is also proved by the cathodic photocurrent spectra (Fig. 9). The band gap estimated from the photocurrent spectra after surface selenization is reduced by $0.18 \mathrm{eV}$ for $\mathrm{CdSe}(3)$ and $0.09 \mathrm{eV}$ for $\mathrm{CdSe}(30)$, remaining unchanged for $\mathrm{CdSe}(80)$ (Table 3).

As can be seen from Fig. 9 (curve 1), the largest quantum efficiency of cathodic photocurrent is observed for $\mathrm{CdSe}(3)$, i.e., for QDs with minimal size. The equilibrium potential of the $\mathrm{Se}_{\mathrm{n}}{ }^{2-} / \mathrm{Se}^{2-}$ redox system measured on Pt-electrode is $-0.35 \mathrm{~V}$. Therefore, $E\left(\mathrm{Se}_{\mathrm{n}}{ }^{2-} / \mathrm{Se}^{2-}\right)$ is located closely to the

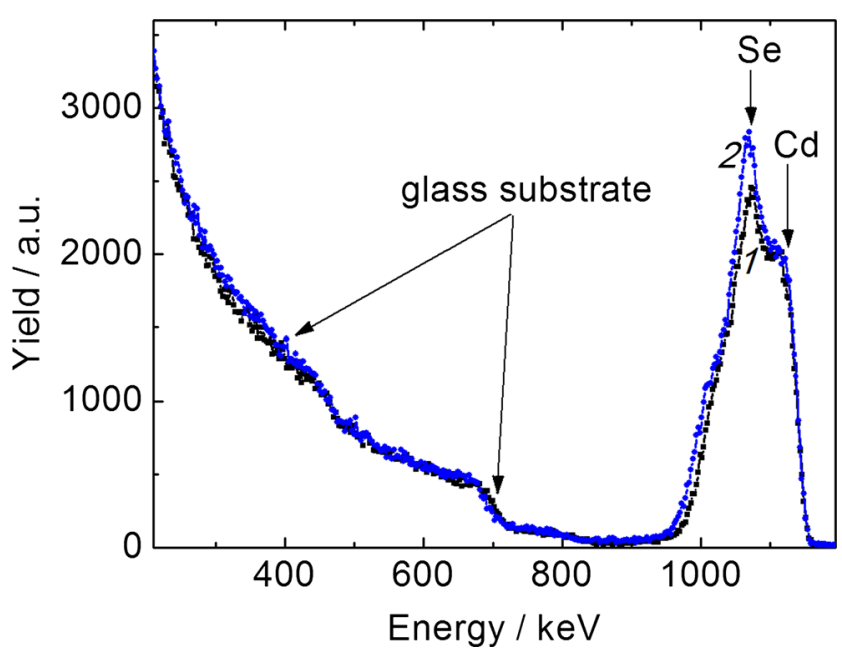

Fig. 8 Rutherford backscattering spectra of $\mathrm{CdSe}(3)$ film before (1) and after (2) treatment in the polyselenide electrolyte 


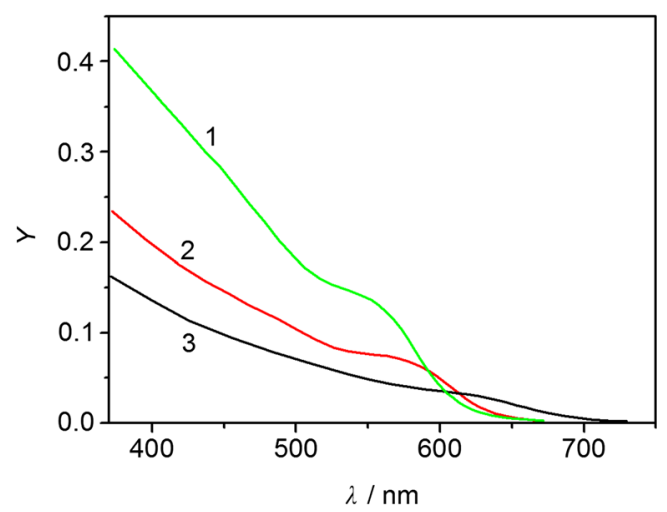

Fig. 9 IPCE spectra of cathodic photocurrent for CdSe electrodes in polyselenide electrolyte at applied potential of -0.5 V. $1 \mathrm{CdSe}(3), 2$ $\mathrm{CdSe}(30)$, and $3 \mathrm{CdSe}(80)$

conduction band edge of CdSe. Thus, small CdSe quantum dots with their increased band gaps have more favorable conduction band energies for injecting photoelectrons to polyselenide anions. In this case, we observe size-dependent electron injection from CdSe quantum dots into electrolyte. A similar situation was observed when the injection of photoelectrons occurred from excited CdSe quantum dots into $\mathrm{TiO}_{2}$ nanoparticles [23].

Recombination losses of photogenerated charges in nanocrystalline CdSe films occur at interparticle boundaries, as well as are associated with possibility of indirect recombination by electron and hole injection into the electrolyte. The latter one can take up to 30-40\% of total efficiency [15] and is related to the parallel passing of associated photoelectrochemical oxidation and reduction reactions [16, 48, 49]. Change of photocurrent sign for $\mathrm{CdSe}(30)$ and $\mathrm{CdSe}(80)$ electrodes occurs under electrochemical polarization (Fig. 7) and the potential of photocurrent switching $\left(E_{\mathrm{sw}}\right)$ correlates with the equilibrium potential of the $\mathrm{Se}_{\mathrm{n}}{ }^{2}$ ${ }^{-} / \mathrm{Se}^{2-}$ redox system. A similar effect was observed earlier for nanocrystalline $\mathrm{BiOI}$ electrodes [50]. It was shown [50] that when electrode potential is equal to $E_{\mathrm{sw}}$, photocurrent is absent due to the recombination of photoholes and photoelectrons with the redox system components, and the value $E_{\mathrm{sw}}$ is determined by equality of exchange currents of anodic and cathodic processes.

It should be noted, that photocurrent switching effect has been already described in the literature for individual semiconductor electrodes [50,51], as well as for semiconductor heterostructures [52, 53]. This effect can be applied in novel logical nanoswitchers [52].

\section{Conclusions}

Photoelectrochemical behavior of the chemical bath deposited CdSe QD films was investigated. Varying of the deposition bath temperature from 3 to $80{ }^{\circ} \mathrm{C}$ resulted in the change of
CdSe nanoparticles average diameter from 4 to $10 \mathrm{~nm}$ and the band gap from 2.26 to $1.81 \mathrm{eV}$. In aqueous $\mathrm{Na}_{2} \mathrm{SO}_{3}$ solution (without dissolved oxygen), the CdSe photoelectrodes generate only anodic photocurrent ( $n$-type behavior), whereas a gradual change of photocurrent from anodic to cathodic occurs after immersion of the films in polyselenide electrolyte containing $\mathrm{Se}_{n}{ }^{2-} / \mathrm{Se}^{2-}$ redox couple. The appearance of cathodic photocurrent is related to Se-termination of the CdSe surface as it was demonstrated by the cadmium underpotential deposition on $\mathrm{CdSe}$ treated with the polyselenide electrolyte. The effect of photocurrent switching depends on the particle size and is most pronounced for CdSe QDs with the minimal size $(d=4 \mathrm{~nm})$ due to more favorable conduction band energies for injecting electrons into $\mathrm{Se}_{\mathrm{n}}{ }^{2-}$ anions. On the contrary, for photoholes injection in the electrolyte (anodic photocurrent) this fact is not important, because the position of the valence band does not vary with the size of the particles.

Cadmium UPD on CdSe was used to evaluate in situ the real surface area of the photoelectrodes, which has turned to be 1-2 orders of magnitude higher than the geometrical surface area. High quantum efficiency of photoelectrochemical processes (IPCE $\sim 40 \%$ ) in the nanocrystalline CdSe photoelectrodes is provided by an effective charge separation at the highly developed semiconductor-electrolyte interface.

Acknowledgments This work was supported by project no. 2/217/GF4 within the state program no. 055 "Scientific and/or scientific and technical activity" (subprogram 101) of the Republic of Kazakhstan.

\section{References}

1. Kamat P (2008) Quantum dot solar cells. Semiconductor nanocrystals as light harvesters. J Phys Chem C 112:18737-18753

2. Alivisatos AP (1996) Semiconductor clusters, nanocrystals, and quantum dots. Science 271:933-937

3. Nozik AJ (2002) Quantum dot solar cells. Phys E 14:115-120

4. Rühle S, Shalom M, Zaban A (2010) Quantum-dot-sensitized solar cells. ChemPhysChem 11:2290-2304

5. Hetsch F, Xu X, Wang H, Kershaw SV, Rogach AL (2011) Semiconductor nanocrystal quantum dots as solar cell components and photosensitizers: material, charge transfer, and separation aspects of some device topologies. J Phys Chem Lett 2:1879-1887

6. Kryukov AI, Stroyuk OL, Kuchmiy SY, Pohodenko VD (2013) Nanophotocatalysis. Akademperiodika, Kiev

7. Bard AJ (1979) Photoelectrochemistry and heterogeneous photocatalysis at semiconductors. J Photochem 10:59-75

8. Kamat PV (2012) Manipulation of charge transfer across semiconductor interface. A criterion that cannot be ignored in photocatalyst design. J Phys Chem Lett 3:663-672

9. Vaneski A, Schneider J, Susha AS, Rogach AL (2014) Aqueous synthesis of $\mathrm{CdS}$ and $\mathrm{CdSe} / \mathrm{CdS}$ tetrapods for photocatalytic hydrogen generation. APL Mater 2:012104

10. Gaponenko SV (2010) Introduction to nanophotonics. Cambridge University Press, Cambridge

11. Talapin DV, Lee JS, Kovalenko MV, Shevchenko EV (2010) Prospects of colloidal nanocrystals for electronic and optoelectronic applications. Chem Rev 110:389-458 
12. Bang JH, Kamat PV (2009) Quantum dot sensitized solar cells. A tale of two semiconductor nanocrystals: CdSe and CdTe. ACS Nano 3:1467-1476

13. Hodes G (2007) Semiconductor and ceramic nanoparticle films deposited by chemical bath deposition. Phys Chem Chem Phys 9: 2181-2196

14. Hodes G, Albu-Yaron A, Decker F, Motisuke P (1987) Threedimensional quantum-size effect in chemically deposited cadmium selenide films. Phys Rev B 36:4215-4221

15. Hodes G, Howell ID, Peter LM (1992) Nanocrystalline photoelectrochemical cells. A new concept in photovoltaic cells. J Electrochem Soc 139:3136-3140

16. Hagfeldt A, Grätzel M (1995) Light-induced redox reactions in nanocrystalline systems. Chem Rev 95:49-68

17. Kronik L, Ashkenasy N, Leibovitch M, Fefer E, Shapira Y, Gorer S, Hodes G (1998) Surface states and photovoltaic effects in CdSe quantum dot films. J Electrochem Soc 145:1748-1755

18. Madelung O (2004) Semiconductors: data handbook. SpringerVerlag, Berlin - Heidelberg

19. Malashchonak MV, Mazanik AV, Korolik OV, Streltsov EA, Kulak AI (2015) Influence of wide band gap oxide substrates on the photoelectrochemical properties and structural disorder of CdS nanoparticles grown by the successive ionic layer adsorption and reaction (SILAR) method. Beilstein J Nanotechnol 6:2252-2262

20. Kozitskiy AV, Stroyuk OL, Kuchmiy SY, Mazanik AV, Poznyak SK, Streltsov EA, Kulak AI, Korolik OV, Dzhagan VM (2014) Photoelectrochemical and Raman characterization of nanocrystalline $\mathrm{CdS}$ grown on $\mathrm{ZnO}$ by successive ionic layer adsorption and reaction method. Thin Solid Films 562:56-62

21. Qu L, Peng X (2002) Control of photoluminescence properties of CdSe nanocrystals in growth. J Am Chem Soc 124:2049-2055

22. Efros AL, Efros AL (1982) Interband light absorption in semiconductor sphere. Soviet Physics Semiconductors 16:772-775

23. Robel I, Kuno M, Kamat PV (2007) Size-dependent electron injection from excited $\mathrm{CdSe}$ quantum dots into $\mathrm{TiO}_{2}$ nanoparticles. J Am Chem Soc 129:4136-4137

24. Beranek R (2011) (Photo)electrochemical methods for the determination of the band edge positions of $\mathrm{TiO}_{2}$-based nanomaterials. Advances in Physical Chemistry 2011:786759

25. Norris DJ, Bawendi MG (1996) Measurement and assignment of the size-dependent optical spectrum in CdSe quantum dot. Phys Rev B 53:16338-16346

26. Wang C, Shim M, Guyot-Sionnest P (2001) Electrochromic nanocrystal quantum dots. Science 291:2390-2392

27. Miyake M, Torimoto T, Sakata T, Mori H, Yoneyama H (1999) Photoelectrochemical characterization of nearly monodisperse CdS nanoparticles-immobilized gold electrodes. Langmuir 15: 1503-1507

28. Rajh T, Mićić OI, Nozik AJ (1993) Synthesis and characterization of surface-modified colloidal CdTe quantum dots. J Phys Chem 97: 11999-12003

29. Jacobsson TJ, Edvinsson T (2012) Photoelectrochemical determination of the absolute band edge positions as a function of particle size for ZnO quantum dots. J Phys Chem C 116:15692-15701

30. Wang LW, Zunger A (1996) Pseudopotential calculations of nanoscale CdSe quantum dots. Phys Rev B 53:9579-9582

31. Jasieniak J, Califano M, Watkins SE (2011) Size-dependent valence and conduction band-edge energies of semiconductor nanocrystals. ACS Nano 5:5888-5902

32. Markus TZ, Wu M, Wang L, Waldeck DH, Oron D, Naaman R (2009) Electronic structure of CdSe nanoparticles adsorbed on $\mathrm{Au}$ electrodes by an organic linker: Fermi level pinning of the HOMO. J Phys Chem C 113:14200-14206
33. Meulenberg RW, Lee JR, Wolcott A, Zhang JZ, Terminello LJ, Buuren T (2009) Determination of the exciton binding energy in CdSe quantum dots. ACS Nano 3:325-330

34. Inamdar SN, Ingole PP, Haram SK (2008) Determination of band structure parameters and the quasi-particle gap of CdSe quantum dots by cyclic voltammetry. ChemPhysChem 9:2574-2579

35. Querner C, Reiss P, Sadki S, Zegorska M, Pron A (2005) Size and ligand effects on the electrochemical and spectroelectrochemical responses of CdSe nanocrystals. Phys Chem Chem Phys 7:3204 3209

36. Kucur E, Riegler J, Urban GA, Nann T (2003) Determination of quantum confinement in CdSe nanocrystals by cyclic voltammetry. J Chem Phys 119:2333-2337

37. Herrero E, Buller LJ, Abruna HD (2001) Underpotential deposition at single surfaces of $\mathrm{Au}, \mathrm{Pt}, \mathrm{Ag}$ and other materials. Chem Rev 101: 1897-1930

38. Kolb DM (1978) In: Gerischer H, CW T (eds) Advances in electrochemistry and electrochemical engineering, vol Vol 11. Wiley, New York

39. Chulkin PV, Aniskevich YM, Streltsov EA, Ragoisha GA (2015) Underpotential shift in electrodeposition of metal adlayer on tellurium and the free energy of metal telluride formation. J Solid State Electrochem 19:2511-2516

40. Ragoisha GA, Streltsov EA, Rabchynski SM, Ivanou DK (2011) Cadmium cathodic deposition on polycrystalline p-selenium: dark and photoelectrochemical processes. Electrochim Acta 56:35623566

41. Mathe MK, Cox SM, Flowers BH, Vaidyanathan R, Pham L, Srisook N, Happek U, Stickney JL (2004) Deposition of CdSe by EC-ALE. J Crystal Growth 271:55-64

42. Colletti LP, Flowers BH, Stickney JL (1998) Formation of thin films of CdTe, CdSe, and CdS by electrochemical atomic layer epitaxy. J Electrochem Soc 145:1442-1449

43. Lister TE, Stickney JL (1996) Formation of the first monolayer of CdSe on Au(111) by electrochemical ALE. Appl Surf Sci 107:153160

44. Gregory BW, Stickney JL (1991) Electrochemical atomic layer epitaxy (ECALE). J Electroanal Chem 300:543-561

45. Trasatti S, Petrii OA (1992) Real surface area measurements in electrochemistry. J Electroanal Chem 327:353-376

46. Chakrapani V, Baker D, Kamat PV (2011) Understanding the role of the sulfide redox couple $\left(\mathrm{S}^{2-} / \mathrm{S}_{\mathrm{n}}{ }^{2-}\right)$ in quantum dot-sensitized solar cells. J Am Chem Soc 133:9607-9615

47. Pathan HM, Lokhande CD (2004) Deposition of metal chalcogenide thin films by successive ionic layer adsorption and reaction (SILAR) method. Bull Mater Sci 27:85-111

48. Bard AJ (1982) Design of semiconductor photoelectrochemical systems for solar energy conversion. J Phys Chem 86:172-177

49. Solarska R, Rutkowska I, Morand R, Augustynski J (2006) Photoanodic reactions occurring at nanostructured titanium dioxide films. Electrochim Acta 51:2230-2236

50. Kazyrevich ME, Malashchonak MV, Mazanik AV, Streltsov EA, Kulak AI, Bhattacharya C (2016) Photocurrent switching effect on platelet-like $\mathrm{BiOI}$ electrodes: influence of redox system, light wavelength and thermal treatment. Electrochim Acta 190:612-619

51. Podborska A, Gawel B, Pietrzak L, Szymanska IB, Jeszka JK, Lasocha W, Szaciłowski K (2009) Anomalous photocathodic behavior of CdS within the Urbach tail region. J Phys Chem C 113: 6774-6784

52. Long M, Beranek R, Cai W, Kisch H (2008) Hybrid semiconductor electrodes for light-driven photoelectrochemical switches. Electrochim Acta 53:4621-4626

53. Bai Z, Zhang Y (2016) Self-powered UV266a 53:4photodetectors based on $\mathrm{ZnO} / \mathrm{Cu}_{2} \mathrm{O}$ nanowire/electrolyte heterojunctions. J Alloys Compd 675:325-330 